\title{
Force Degradation High Performance Liquid Chromatographic HPLC Assay Method of Apixaban in Pharmaceutical Preparations
}

\author{
Suresh* and K. Rambabu \\ Department of Chemistry, RVR \& JC College of Engineering, Guntur, Andra Pradesh, India. \\ Corresponding author emmil: thuta.suresh@gmail.com
}

\begin{abstract}
The current paper describes the measure of apixaban was accomplished on a Thermo BDS, C8, 150 X 4.6, 5 $\mu$, and buffer ( $\mathrm{pH} 4.5$ ) and Acetonitrile at 60:40\% $/ \mathrm{v}$ ratio as the mobile phase, at a stream pace of $1.0 \mathrm{ml} \mathrm{min}^{-1}$. HPLC recognition of elute was gotten by a photodiode cluster detector (DAD) which was set at $259 \mathrm{~nm}$. ICH rules were followed for approval of proposed strategy with respect to particularity, affectability, exactness, linearity, precision, framework appropriateness and vigor. Alignment bends of apixaban were made in the scope of 8.0-48 $\mu \mathrm{g} . \mathrm{mL}^{-1}$ with LOD and LOQ of $0.20 \mu \mathrm{g} . \mathrm{mL}^{-1}$ and $0.24 \mu \mathrm{g} . \mathrm{mL}^{-1}$ separately. A pixaban strength was assessed under different ICH constrained corruption conditions and it was discovered to be effortlessly debased in acidic and basic conditions. The assurance of apixaban in drug measurements structures was directed with the portrayed technique and showed mean rate recuperation of 100.54 ( $\mathrm{n}=3$ ), individually.
\end{abstract}

KEY WORDS: RP-HPLC, APIXABAN, STABILITY-INDICATING,STRESS DEGRADATION.

\section{INTRODUCTION}

Apixaban, 1-(4-methoxyphenyl)-7-oxo-6-[4-(2oxopiperidin-l-yl) phenyl]-4,5,6,7-tetrahydro- $1 \mathrm{H}-$ pyrazolo [3, 4-c] pyridine- 3 - carbo-xamide (Figure 1) is an oral anticoagulant used to treat the stroke caused by a blood clot with heart rhythm disorder (Atrial fibrillation) (Cada et al., 2013 (Apixaban, 2019 \& 2021) (Raghavan et al., 2009). Scarcely only three insightful techniques (Prabhune et al., 2014) (Katari and Jonnalagadda 2020) (Ani et al., 2021) detailed in the writing for the substance assessment of apixaban in drug substances utilizing liquid chromatography (HPLC).The primary aim of introduced paper is to assess apixaban soundness in accordance with the relevant rules of ICH(ICH Q2 (R1) 2005) using a full approved RP-HPLC technique in exposing the examined medication to a wide scope of stress conditions.

Biosc Biotech Res Comm P-ISSN: 0974-6455 E-ISSN: 2321-4007

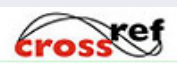

Identifiers and Pagination

Year: 2021 Vol: 14 No (9) Special Issue

Pages: 253-258

This is an open access article under Creative

Commons License Attribn 4.0 Intl (CC-BY).

DOI: $h t t p: / / d x$.doi.org/10.21786/bbrc/14.9.47

\section{MATERIAL AND METHODS}

Instrumentation: Agilent 1120 series consisting 2 channels. Auto sampler with one rack it has 100 vials. Auto injector has capacity to inject $0.1 \mu \mathrm{L}$ to $100 \mu \mathrm{L}$. UV-Vis Detector. Thermostat column compartment connected it has a capacity to maintain $4^{\circ} \mathrm{C}$ to $80^{\circ} \mathrm{C}$ column temperature. Agilent 1120 HPLC System is equipped with Ezchrome Elite software. Orthophosphoric acid, Acetonitrile (HPLC grade), Milli-Q water. Hydrochloric acid (AR), sodium hydroxide (AR-grade), Hydrogen peroxide were procured from Merck-R, and Sigma -J.

Mobile phase preparation: Mix buffer ( $\mathrm{pH} 4.5)$ and Acetonitrile at $60: 40 \% \mathrm{v} / \mathrm{v}$ ratio was used. Prior to use it was sonicated and degassed sing vacuum filtration through 0.45 micron membrane filter.

Buffer preparation (pH 4.5): Prepare $1.625 \mathrm{gm}(0.02 \mathrm{M})$ Potassium di hydrogen orthophosphate \&t $0.3 \mathrm{gm}$ of diPotassium hydrogen orthophosphate in $550 \mathrm{ml}$ of HPLC water. The $\mathrm{pH}$ of the buffer adjusted to 4.5 with diluted orthophosphoric acid.

Standard stock solution preparation: Weigh and transfer 20mg of Apixaban working standard into $50 \mathrm{~mL}$
Article Information

Received: $17^{\text {th }}$ Apr 2021

ccepted after revision: $20^{\text {th }}$ June 2021 
volumetric flask, add $25 \mathrm{~mL}$ of diluent and sonicate to dissolve and dilute to volume with diluent.

Standard preparation: Transfer $1.0 \mathrm{~mL}$ of standard stock solution into $10 \mathrm{~mL}$ volumetric flask and dilute to volume with diluent. The concentration of apixaban was calculated by calibration graph prepared with stock solution.

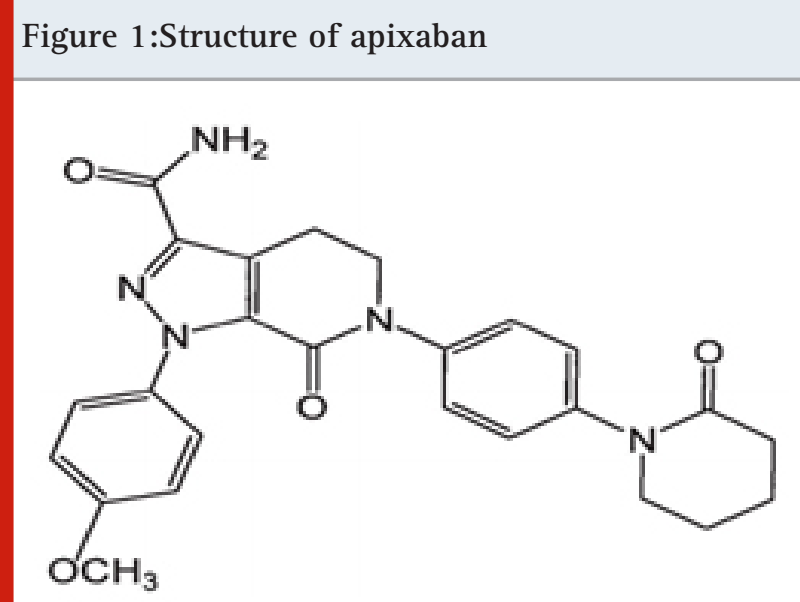

Sample Preparation: No pretreatment like timeconsuming extraction or evaporation step was performed for specimen preparation. Finely grind pre weighed 20 tablets of apixaban. Transfer grinded sample quantitatively equivalent to $20 \mathrm{mg}$ of apixaban into $50 \mathrm{~mL}$ volumetric flask add $25 \mathrm{~mL}$ of diluent, sonicate to dissolve for 10 minutes and dilute to volume with diluent. Further filter the solution through filter paper. Dilute 0.8 $\mathrm{ml}$ of filtrate to $10 \mathrm{ml}$ with mobile phase. All solutions were filtered through $0.45 \mu \mathrm{m}$ Millipore membrane filters before injections into the HPLC system. Experiments were realized under the same conditions as employed for the apixaban pharmaceutical preparations.

Figure 2:Validated chromatogram of apixaban

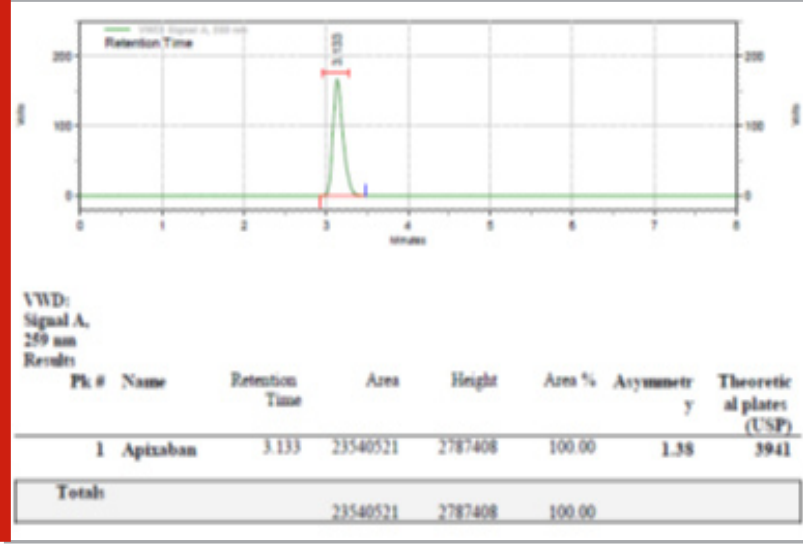

Stress studies: Stability indicating analytical method of apixaban has been developed according to the ICH guideline. Degradation was carried out in following conditions:
Acidic -Drug was subjected to $1 \mathrm{M} \mathrm{HCl}$ in a water bath at $100^{\circ} \mathrm{C}$ for $3 \mathrm{hrs}$. Solution was neutralized by sodium hydroxide and diluted with mobile phase. Peak area of apixaban was observed when chromatographed after exposing at $70^{\circ} \mathrm{C}$ for $8 \mathrm{hr}$.

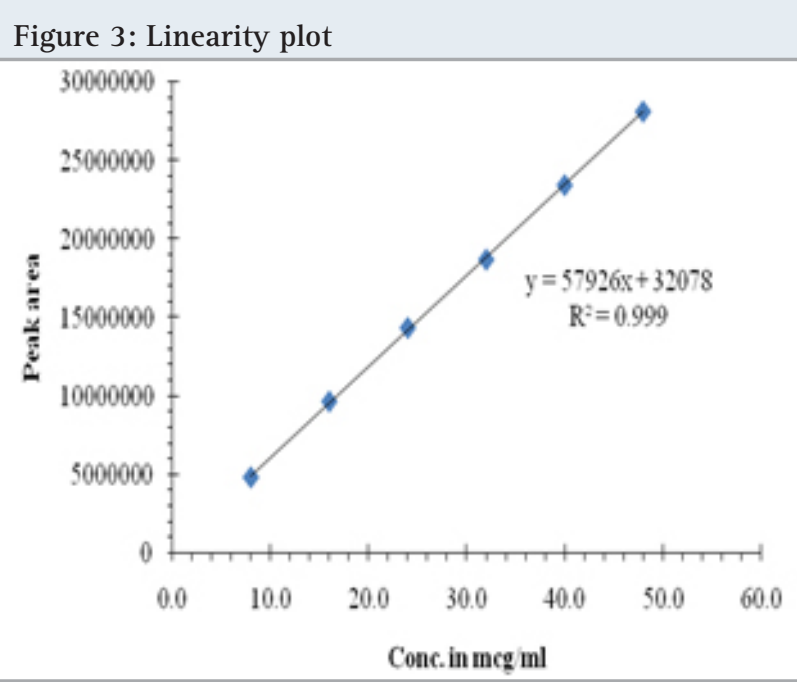

Alkaline -Drug was also subjected to $0.5 \mathrm{M} \mathrm{NaOH}$ at $100^{\circ} \mathrm{C}$ for 3hrs. Solution was neutralized by $0.5 \mathrm{M} \mathrm{HCl}$ diluted with mobile phase.

Oxidation - Drug was subjected to $6 \%$ hydrogen peroxide for $48 \mathrm{hrs}$ at room temperature.

Thermal - Drug was subjected to thermal degradation at $80^{\circ} \mathrm{C}$ for 8 days.

Photo-stability condition-Drug was subjected to degradation in photostability chamber for 8 days.

\section{RESULTS AND DISCUSSION}

HPLC Development And Optimization: Several parameters that can affect chromatographic separation were evaluated and optimized. These parameters included scanning of different wavelengths, experimenting with various types of the aqueous phase, changes of the mobile phase $\mathrm{pH}$, different types and ratio of organic modifier added and flow rate.

\section{Chromatographic conditions:}

\section{Column}

Flow Rate

Wave length

Column temperature

Injection volume

Diluent

Elution type

Needle wash solution

: Thermo BDS, C8, $150 \mathrm{X} 4.6,5 \mu$.

: $1.0 \mathrm{ml} / \mathrm{min}$

: $259 \mathrm{~nm}$

: $30^{\circ} \mathrm{C}$

$: 20 \mu \mathrm{L}$

: Mobile Phase

: Isocratic

: Water: Acetonitrile

(90:10\%v/v)

Strategy: In our investigation, chromatographic separation was affected utilizing an isocratic mode with a C18 column. The mobile phase made out of combination 
of buffer ( $\mathrm{pH} 4.5$ ) and Acetonitrile at 60:40\%v/v ratio at a steady stream pace of $1.0 \mathrm{~mL} / \mathrm{min}$. The eluate was checked at a set frequency of $259 \mathrm{~nm}$ at RT. Every infusion run was repeated multiple times, with an infusion volume of $20 \mu \mathrm{L}$. Absolute run season of each example infusion was roughly $8 \mathrm{~min}$, and evaluation of the segments under investigation was accomplished utilizing the all out peak areas of the researched segments.

Figure 4 a: Acid stress studies chromatogram

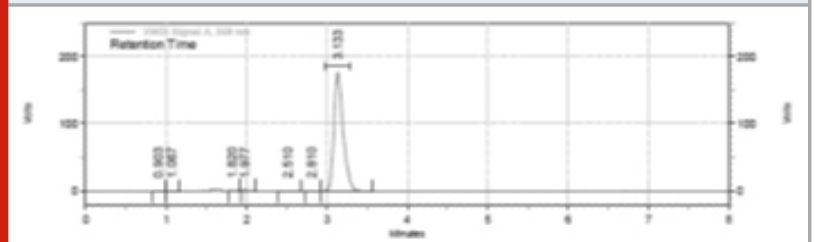

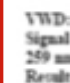

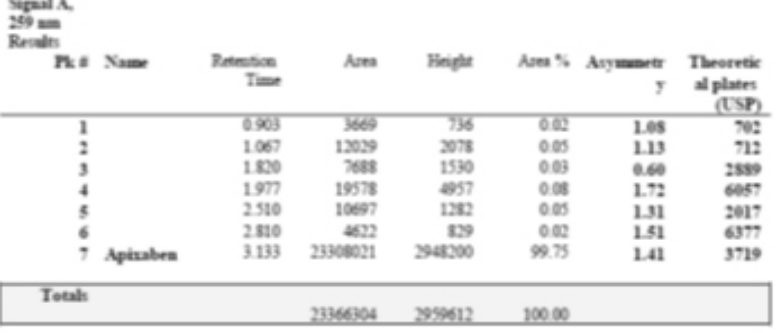

Figure 4 b: Base degradation chromatogram

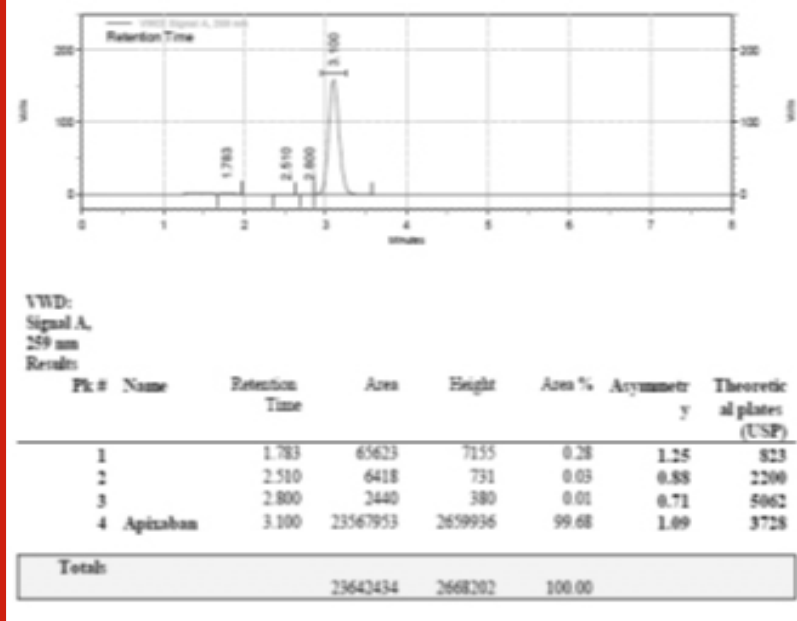

Method validation: To demonstrate appropriateness of method for the predetermined purpose, validation of the developed RP-HPLC method was done as per ICH guidelines (ICH Q2 (R1) 2005).

System suitability: The system suitability was checked by infusing six replicate injections of apixaban $(40 \mu \mathrm{g} /$ $\mathrm{mL}$ ) under optimized chromatographic conditions. The system was deemed to be suitable for use, as the tailing factors and resolutions for apixaban were less than 1.4 and more than 4.0, respectively. System suitability results are given in Table 1 .
Figure 4 c: Oxidative degradation chromatogram
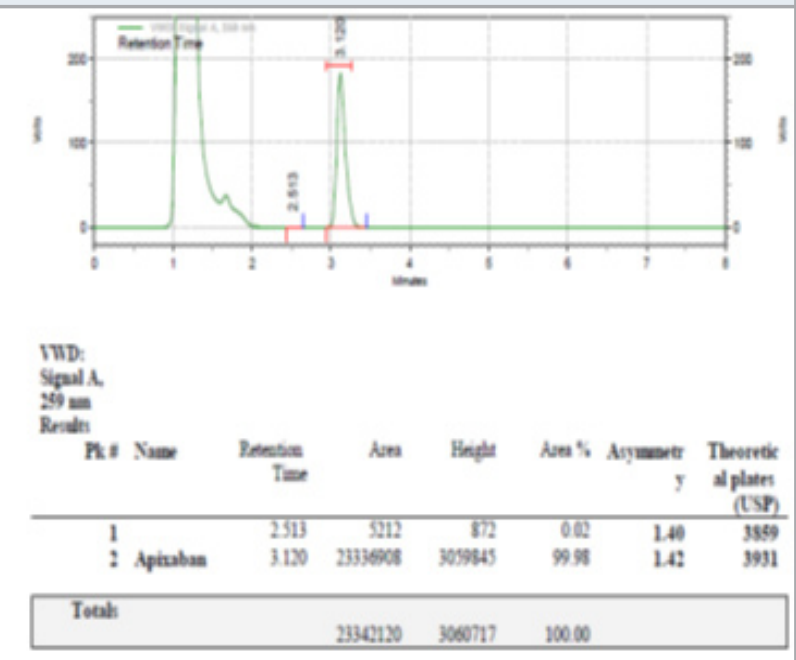

Figure $4 \mathrm{~d}$ : Thermal degradation chromatogram

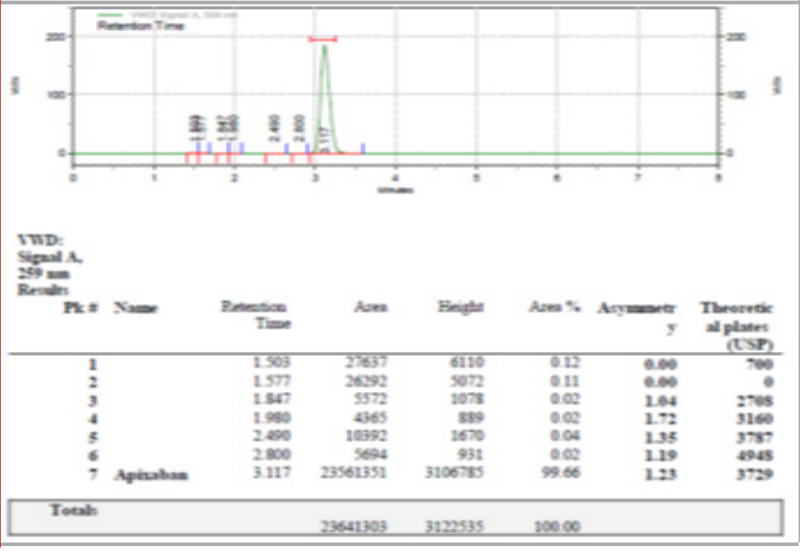

Table 1 . System suitability studies

\begin{tabular}{|l|c|c|c|c|}
\hline $\begin{array}{l}\text { Sample Name } \\
\text { Blank }\end{array}$ & $\begin{array}{c}\text { Rt } \\
-\end{array}$ & $\begin{array}{c}\text { Area } \\
-\end{array}$ & $\begin{array}{c}\text { Theoretical } \\
\text { Plates }\end{array}$ & Asymmetry \\
\hline $\begin{array}{l}\text { Apixaban, } \\
\text { Standard }\end{array}$ & 3.133 & 23535298 & 3941 & 1.38 \\
\hline Placebo & - & - & & \\
\hline Sample & 3.13 & 23546852 & & \\
\hline
\end{tabular}

Linearity: Accurately measured volumes of the apixaban standard solution $(100 \mu \mathrm{g} / \mathrm{mL})$ were successively transferred into six $10 \mathrm{~mL}$ volumetric flasks. $20 \mu \mathrm{L}$ aliquots of each solution were chromatographed three times and analysis was performed by optimized method. The regression equation was derived from the plot of average area of apixaban peak against the concentration of apixaban area were submitted to linear regression analysis to obtain the regression equation and correlation coefficient. Table 2 presents the data of linearity and Figure 3 shows calibration curve for apixaban. The calibration graph was linear over the concentration range $8.0-48 \mu \mathrm{g} / \mathrm{mL}$ of apixaban ( $\mathrm{r} 2=0.9996)$. The 
calibration results revealed a good linear relationship of peak area of apixaban over the concentration range of $8.0-48 \mu \mathrm{g} / \mathrm{mL}$.

Table 2. Linearity studies

\begin{tabular}{|l|c|}
\hline Conc(mcg) & Area \\
\hline 8.0 & 4849783 \\
\hline 16.0 & 9683579 \\
\hline 24.0 & 14371967 \\
\hline 32.0 & 18721575 \\
\hline 40.0 & 23462427 \\
\hline 48.0 & 28151143 \\
\hline r2 & 0.9999 \\
\hline LOD & $0.600 \mu \mathrm{g} / \mathrm{ml}$ \\
\hline LOQ & $2.00 \mu \mathrm{g} / \mathrm{ml}$ \\
\hline
\end{tabular}

Table 3. Stress degradation studies

\begin{tabular}{|l|c|c|c|}
\hline $\begin{array}{l}\text { Degradation } \\
\text { Studies }\end{array}$ & Assay & $\begin{array}{c}\text { Assay } \\
\text { Value }\end{array}$ & $\begin{array}{c}\text { \% Of Net } \\
\text { Degradation }\end{array}$ \\
\hline Acid & 97.87 & 100.54 & 2.672 \\
\hline Base & 97.114 & 100.54 & 3.426 \\
\hline $\mathrm{H}_{2} \mathrm{O}_{2}$ & 97.097 & 100.54 & 3.443 \\
\hline $\mathrm{UV}$ & 96.307 & 100.54 & 4.233 \\
\hline Thermal & 97.635 & 100.54 & 2.905 \\
\hline
\end{tabular}

Limit of Detection and Limit of Quantitation: Standard deviation of y intercept of calibration curve of linear lower concentrations $(\mathrm{N})$ and slope $(\mathrm{S})$ of the calibration curve were calculated and using their values LOD and LOQ were estimated as per ICH guideline. LOD and LOQ were estimated as per ICH guidelines using mathematical formula. Obtained. value for LOD was $0.600 \mu \mathrm{g} / \mathrm{mL}$ and obtained value for LOQ was $2.00 \mu \mathrm{g} / \mathrm{mL}$ respectively.

Stress studies: The forced degradation studies in acid, alkaline, photolytic, heat, and oxidative conditions, resulted in non significant decrease of the area without any detectable eluting degradation product. Under these conditions, 97.87, 97.114, 97.097, 96.307 and 97.635\% of apixaban were recovered, respectively. The results (Table 3) of HPLC method for stress samples, including separation of the degradation products produced of apixaban in indicated the proposed method is stabilityindicating. Chromatograms of apixaban after degradation with acid, alkaline, oxidative, heat, and photolytic conditions are displayed in Figures 4a -4e.

Repeatability: To assess repeatability of the method, chromatographic analysis of six injections of $40 \mu \mathrm{g} /$ $\mathrm{mL}$ apixaban solutions was performed. The average, standard deviation and \% RSD for retention time and area of apixaban peak were estimated. Table 4 presents results of repeatability. \% RSD of retention time and area of apixaban determination was found less than $2 \%$ that proves the repeatability of the developed HPLC method.

Table 4. Repeatability Studies

\begin{tabular}{|l|c|c|c|}
\hline S No & Name & RT & Area \\
\hline 1 & Method Precision-1 & 3.14 & 23522656 \\
\hline 2 & Method Precision-2 & 3.163 & 23647919 \\
\hline 3 & Method Precision-3 & 3.133 & 23549208 \\
\hline 4 & Method Precision-4 & 3.113 & 23526105 \\
\hline 5 & Method Precision-5 & 3.13 & 23436418 \\
\hline 6 & Method Precision-6 & 3.157 & 23507797 \\
\hline Avg & & 3.139 & 23531684 \\
\hline Std Dev & & 0.018 & 68668.04 \\
\hline \%RSD & & 0.586 & 0.292 \\
\hline
\end{tabular}

Table 5. Accuracy studies

\begin{tabular}{|l|c|c|}
\hline 80\% accuracy & RT & Area \\
\hline Accuracy-80-1 & 3.13 & 18762329 \\
\hline Accuracy-80-2 & 3.14 & 18741277 \\
\hline Accuracy-80-3 & 3.107 & 18735915 \\
\hline Avg & 3.126 & 18746507 \\
\hline & & 80.35 \\
\hline amt added(mg) & & 16.00 \\
\hline amt Recoverd(mg) & & 16.14 \\
\hline \%Recovery & & 100.86 \\
\hline $100 \%$ accuracy & & \\
\hline Accuracy-100-1 & 3.103 & 23307056 \\
\hline Accuracy-100-2 & 3.102 & 23343824 \\
\hline Accuracy-100-3 & 3.103 & 23372929 \\
\hline Avg & 3.103 & 23341270 \\
\hline & & 100.04 \\
\hline amt added(mg) & & 20.00 \\
\hline amt Recoverd(mg) & & 19.99 \\
\hline \%Recovery & & 99.96 \\
\hline 120\% accuracy & & \\
\hline Accuracy-120-1 & 3.12 & 28178075 \\
\hline Accuracy-120-2 & 3.117 & 28117262 \\
\hline Accuracy-120-3 & 3.123 & 28195873 \\
\hline Avg & 3.120 & 28163737 \\
\hline & & 120.71 \\
\hline amt added(mg) & & 24.00 \\
\hline amt Recoverd(mg) & & 24.24 \\
\hline \%Recovery & & 101.01 \\
\hline Acciacy & & \\
\hline
\end{tabular}

Accuracy: In the prepared test solution mixture, apixaban standard solution was added at 80\%, 100\% and $120 \%$ concentration level. $20 \mu \mathrm{l}$ of each solution were injected three times and were chromatographed. 
When the method was used for analysis of apixaban from previously analysed laboratory mixture solution after spiking of 80, 100 and 120\% apixaban standard, the recovery was found $99.96-101.01 \%$. Table 5 presents the results of accuracy determination.

Robustness: The experimental conditions of the method were deliberately changed to determine the robustness. The wavelength $(259 \mathrm{~nm} \pm 2 \%)$ and mobile phase flow rate $(1.0 \pm 0.1 \mathrm{~mL} / \mathrm{min}$.) were varied. In each case, and $\%$ RSD of area of apixaban peak and retention time was calculated. Comparison of the retention time and area of apixaban peak were done with that obtained under the optimized method, also. It was found that method was robust regarding any minor deviation in the column temperature. Table 6 shows the results of the robustness.

Ruggedness: A $20 \mu \mathrm{l}$ aliquot of fixation $10 \mu \mathrm{g} / \mathrm{ml}$ was infused to consider the unpleasantness of apixaban by two particular sensible logical specialists (Analyst-1 and

\begin{tabular}{|c|c|c|c|}
\hline \multicolumn{4}{|c|}{ Table 6. Robustness studies } \\
\hline S No & Parameter & RT & Area \\
\hline 1 & Standard & 3.17 & 23518790 \\
\hline 2 & Robustness-Flow-1 & 3.883 & 29190915 \\
\hline 3 & Robustness-Flow-2 & 2.620 & 19483082 \\
\hline 4 & Robustness-nm-1 & 3.110 & 22787010 \\
\hline 5 & Robustness-nm-2 & 3.117 & 23990725 \\
\hline
\end{tabular}

Analyst-2) and the results were recorded and are in the good reach for apixaban. The results (Table 7) exhibited the $\%$ RSD was less than $2 \%$ separately.

Table 7. Ruggedness Study

\begin{tabular}{|l|cc|c|}
\hline S No & $\begin{array}{c}\text { Ruggedness-Day-1 } \\
\text { Name }\end{array}$ & RT & Area \\
\hline 1 & Ruggedness-Day-1-1 & 3.100 & 23604447 \\
\hline 2 & Ruggedness-Day-1-2 & 3.143 & 23504066 \\
\hline 3 & Ruggedness-Day-1-3 & 3.127 & 23566316 \\
\hline 4 & Ruggedness-Day-1-4 & 3.110 & 23532889 \\
\hline 5 & Ruggedness-Day-1-5 & 3.140 & 23535350 \\
\hline 6 & Ruggedness-Day-1-6 & 3.100 & 23502240 \\
\hline Avg & & 3.120 & 23540885 \\
\hline Std Dev & & 0.019 & 39065.36 \\
\hline RSD & & 0.621 & 0.166 \\
\hline & & & \\
\hline S No & Ruggedness-Day-2 & \\
\hline 1 & Name & RT & Area \\
\hline 2 & Ruggedness-Day-2-1 & 3.127 & 23591751 \\
\hline 3 & Ruggedness-Day-2-2 & 3.117 & 23589267 \\
\hline 4 & Ruggedness-Day-2-4 & 3.113 & 23614793 \\
\hline 5 & Ruggedness-Day-2-5 & 3.143 & 23623894 \\
\hline 6 & Ruggedness-Day-2-6 & 3.12 & 23604438 \\
\hline Avg & & 3.122 & 23602080 \\
\hline Std Dev & & 0.011 & 14851.38 \\
\hline RSD & & 0.367 & 0.063 \\
\hline
\end{tabular}

Table 8. Assay Calculation for Apixaban

\begin{tabular}{|c|c|c|c|c|c|c|c|c|}
\hline 23508743 & 20.1 & 1 & 50 & 10 & 99.8 & 120.5 & $\mathrm{mg} /$ tab & \% Of Assay \\
\hline 23534632 & 50 & 10 & 480.3 & 1 & 100 & & 5.03 & 100.54 \\
\hline
\end{tabular}

Application To Pharmaceutical Preparations: There is no chromatographic interference found for tablet dosage forms with internal standard, formulation components. The results given in Table 8 indicated good accuracy of apixaban for pharmaceutical preparations.

\section{CONCLUSION}

The present work described the development of a validated stability-indicating assay HPLC approach to determine apixaban for pharmaceutical preparations using UV detection mode. The chromatographic conditions were finally optimized on Thermo BDS, C8, 150 X 4.6, 5u, and buffer ( $\mathrm{pH} 4.5)$ and Acetonitrile at 60:40\%v/v ratio as the mobile phase, at a stream pace of $1.0 \mathrm{ml}$ min-1 and UV detection at $259 \mathrm{~nm}$. The developed method was found to be selective, sensitive, precise, linear, accurate, and reproducible and stability indicative for determining the apixaban in pharmaceutical preparations.

\section{ACKNOWLEDGEMENT}

The authors are thankful to Department of Chemistry, RVR \& JC Engineering College, Guntur, A.P, India for providing encouraging environment and facilities for research work.

\section{REFERENCES}

Apixaban Monograph for Professionals. Drugs.com. American Society of Health-System Pharmacists. Retrieved 27 March

Apixaban - Drug Usage Statistics”. ClinCalc. Retrieved 18 February.

Al-Ani, M. Hamad, R. Al-Shdefat, K. Mansoor, F. Gligor and W. A. Dayyih, (2021). Development and validation of a stability indicating RP-HPLC method of apixaban in commercial dosage form, International Journal of Pharmaceutical Sciences and Research; 12(1): 241251. 
Cada, Dennis J.; Levien, Terri L.; Baker, Danial E. Apixaban. (2013). Hospital Pharmacy;48 (6): 494-511. ICH Q2 (R1). 2005 Validation of Analytical Procedure: Text and Methodology. International Conference on Harmonization.

Katari VB and Jonnalagadda SB. (2020). Stability indicating RP HPLC method development and validation for determination of nine impurities in apixaban tablet dosage forms. Robustness study by quality by design approach. Biomed Chromatogr; 34(1): e4719.
Raghavan N, Frost CE, Yu Z, He K, Zhang H, Humphreys WG, Pinto D, Chen S, Bonacorsi S, Wong PC, Zhang D. (2009). Apixaban metabolism and pharmacokinetics after oral administration to humans. Drug Metab Dispos; 37(1):74-81.

Prabhune SS, Jaguste RS, Kondalkar PL and Pradhan NS. (2014). Stability-Indicating High Performance Liquid Chromatographic Determination of Apixaban in the Presence of Degradation Products. Sci Pharm; 82(4):777-85. 